\title{
Maternal perception of breastfeeding in children with unilateral cleft lip and palate: a qualitative research work
}

\section{Ana María María Cerón-Zapata ( $\square$ aceron@ces.edu.co )}

Universidad CES https://orcid.org/0000-0002-2021-9419

\section{Cecilia María Martínez-Delgado}

Universidade de Coimbra Centro de Estudos Sociais

Gloria Emilia Calderón-Higuita

Universidad CES

\section{Research}

Keywords: perception, feelings, experiences, cleft lip and palate, presurgical orthopedics, nasoalveolar molding

Posted Date: August 27th, 2020

DOl: https://doi.org/10.21203/rs.3.rs-65355/v1

License: (c) (i) This work is licensed under a Creative Commons Attribution 4.0 International License. Read Full License 


\section{Maternal perception of breastfeeding in children with unilateral cleft lip and palate: a qualitative research work}

Cerón-Zapata Ana María D.D.S. Pediatric Dentist, Msc Dental Science, Professor Universidad CES. E-mail: aceron@ces.edu.co

Martínez-Delgado Cecilia María D.D.S, Epidemiology Specialist, Msc University Direction. Professor Universidad CES. E-mail: cmariamar@hotmail.com

Calderón-Higuita Gloria Emilia Nutritionist, Human Nutrition Specialist. Breast feeding certificate consultant. E-mail: gloria.calderon@hotmail.com

Corresponding author:

Address: Calle 10 A \# 22-04

Medellín, Colombia, South America

E-mail: aceron@ces.edu.co 


\section{ABSTRACT}

Background: Unilateral cleft lip and / or palate (UCLP) is one of the most common congenital craniofacial abnormalities. The objective of this study was to describe maternal perception of breastfeeding in children with unilateral cleft lip and palate and to assess the role of breastfeeding counseling. Methods: Qualitative descriptive method and phenomenological analysis were used to analyze the narratives. 28 mothers of patients with nonsyndromic UCLP treated with Nasoalveolar molding (NAM) between April 2015 and April 2017 were strategically selected and interviewed. Framework analysis was conducted for qualitative data. The CES University ethical committee approved the study. Results: The findings resulted in six main categories. First, contact with the CLP program, access to early diagnosis and timely treatment, perceptions of parents about health personnel on breastfeeding of CLP patients, perceptions of mothers toward breastfeeding, perception of advantages and disadvantages of the NAM technique regarding breastfeeding and assessment of the CLP program. Conclusion: The participants related difficulties with breastfeeding. Mothers acknowledged the clinical results when using the NAM obturator, as well as the support provided by the breastfeeding consultant.

Key Words: perception, feelings, experiences, cleft lip and palate, presurgical orthopedics, nasoalveolar molding. 


\section{Introduction}

Cleft lip and/or palate (CLP) is one of the most common congenital craniofacial anomalies and may produce in these patients esthetic, functional and emotional disorders(1) . It shows a prevalence of one per 1.000 live births(2). This condition affects the patient and his/her family causing difficulties in emotional and social development(3) feeding(4), breathing and the development of speech(5), occlusion(6) and physical appearance(7). Therefore, initial orientation to parents is important to understand and assume such condition(3)

Exclusive maternal breastfeeding is the best option to assure that the infant receives the amount of essential nutrients needed for growth and development during the first six months of life(8). In addition, breast milk is the main choice to prevent adverse health conditions and promote intellectual and language development(9). One of the complications exhibited by children with CLP is feeding; an inability to create seal around the nipple during breastfeeding has observed which leads to failure to generate enough negative intraoral pressure during suction(10). This situation will eventually aggravate the nutritional state and development of the newborn(11).

Current advances in treatment protocols for CLP, involve pre-surgical orthopedics, including nasoalveolar molding (NAM) obturators, as an alternative for improving the quality of the reparation process, since they actively improve the affected nostril and passively the alveolar segments(12-14). However, the treatment protocol has observed that breastfeeding still presents difficulties, some of them arising from the perception of mothers, such as discomfort to the infant and the idea that the child is still hungry $(2,11)$. Even though research, 
including quantitative approaches, has focused on the first reactions to the diagnosis and measurement of stress levels during the first years of life $(15,16)$, qualitative investigations that assess the perception of mothers around breastfeeding and CLP are scarce.

Qualitative studies with an exploratory phenomenological approach, look to understand the social phenomena from the perspective of the interviewed person, their experience, their relationships, motivations or intentions, beliefs and the significance of their experiences in a specific situation (17).

Therefore, the purpose of this investigation is to describe maternal perception of breastfeeding in children with unilateral cleft lip and palate and to assess the role of breastfeeding counseling.

\section{Materials and Methods}

Institutional approval was obtained from the Ethics Committee of CES University, through minute number 7429 September 29, 2014. All the mothers signed the applicable informed consent before the data collection.

The study was a qualitative study with exploratory phenomenological approach; the researchers tried to understand the perspective of the interviews, their relationships, motivations and the experiences in a specific situation: breastfeeding their children with unilateral cleft lip and palate treated with NAM, after breastfeeding counseling.

Semi-structured interviews were applied to gather the meaning of the research proposal to 28 mothers of children with non-syndromic unilateral cleft lip and/or 
palate (UCLP), with prenatal (32\%) and postnatal diagnosis (68\%) who consulted to receive early orthopedic treatment with an MNA obturator in the Clínica Noel Foundation interdisciplinary CLP program in Medellín, Colombia, between April 2015 and April 2017. All mothers were born in Colombia, as different cultures have different attitudes to CLP and the authors wished to focus on issues relating to Colombian culture.

\section{Selection criteria}

Mothers of patients between 0 and 2 months of age with either prenatal or postnatal diagnosis of non-syndromic UCLP were included. Mothers who could not attend scheduled periodic appointments were excluded.

Before the interviews, mothers received orientation by a certified international breastfeeding consultant $(\mathrm{GECH})$ regarding the breastfeeding process, generalities of the NAM treatment and detailed oral hygiene and diet counseling. Their UCLP's children received treatment with NAM.

Mothers were divided in two groups. The first group received prenatal information about the process of maternal breastfeeding by an international breastfeeding consultant using a personal education program. The second group received the same information postnatally, since they were unable to arrive at the CPL program prenatally.

\section{Data collection}

Two field worker training sessions covered research ethics, obtained informed consent and data collection, with the strongest focus being on developing qualitative interview skills. Fieldworkers underwent extensive practice conducting 
interviews using role-plays and applying the pilot test. Four pilot interviews were carried out before the interviewer could strive to vary the focus of the phenomena under study. During data collection, researchers listened to interviews on an ongoing basis to monitor quality of interview skills, and feedback given to fieldworkers as necessary. The participants were encouraged to describe their feelings and experiences as fully and as deeply as possible. During the interview, they were asked to give examples and to clarify ideas. The interviews lasted between 60-90 minutes and were digitally recorded and transcribed by the interviewer.

Baseline data was collected using a structured quantitative questionnaire, which included information about participants' sociodemographic characteristics and their infant feeding plans.

\section{Data analysis}

Mothers were requested in-depth interview guides to state whether they planned to feed their baby breastmilk only, formula milk only, or both breast and formula milk.

Two investigators carried out independent data analyses to establish their consistency and reliability. Results were compared and minor variations discussed, reviewed and resolved.

To preserve anonymity, codes were assigned to each participant based on the group. Audio recordings and transcripts were stored at University CES in a password protected file. In accordance with the methodology, transcripts were 
coded according to preliminary and emerging categories were analyzed in order to compare results and reach conclusions (Table 1).

Table 1. Summary of the categorization of the information provided by the mothers interviewed

\begin{tabular}{|c|c|c|}
\hline Topic & Codification & Analysis categories \\
\hline $\begin{array}{l}\text { Remission from the specialist } \\
\text { Recommendation of friends }\end{array}$ & Arrival to the program & First contact with the program \\
\hline Diagnosis pre or postnatal & $\begin{array}{l}\text { Moment of diagnosis of the } \\
\text { baby }\end{array}$ & $\begin{array}{l}\text { Access to early diagnosis } \\
\text { and timely treatment }\end{array}$ \\
\hline $\begin{array}{l}\text { Instructions on feeding the } \\
\text { health personnel at the time } \\
\text { of the child's birth CLP }\end{array}$ & $\begin{array}{l}\text { Contact with health } \\
\text { personnel regarding food }\end{array}$ & $\begin{array}{l}\text { Perception of health } \\
\text { personnel to breastfeeding of } \\
\text { the patient CLP }\end{array}$ \\
\hline $\begin{array}{l}\text { Feelings, difficulties, facilities } \\
\text { of the breastfeeding process }\end{array}$ & $\begin{array}{l}\text { Experiences with } \\
\text { breastfeeding process }\end{array}$ & $\begin{array}{l}\text { Perceptions about } \\
\text { experience of breastfeeding }\end{array}$ \\
\hline $\begin{array}{l}\text { Ease, difficulty, advantages } \\
\text { and disadvantages of the } \\
\text { nasoalveolar molding }\end{array}$ & Using the obturator with NAM & $\begin{array}{l}\text { Perception of advantages } \\
\text { and disadvantages of the } \\
\text { nasoalveolar molding (NAM) } \\
\text { technique }\end{array}$ \\
\hline $\begin{array}{l}\text { Feeling of the process in } \\
\text { general terms }\end{array}$ & Program score & Program evaluation \\
\hline
\end{tabular}

Information collected reached saturation categories, meaning that the information did not reply and did not provide a new topic or intensify it. 
Analysis of the interview data was based on predetermined research themes (drawn from the interview guide), as well as inductive themes that emerged from the interview data (18). The data was grouped into analytical categories in order to organize the information, and finally contribute to the writing the findings.

Framework analysis comprised five stages, beginning with a process of familiarization with the transcripts to gain an overview of the content. This was followed by the development of an analytical framework based on identified research questions, as well as on themes that emerged. This framework was then applied to the individual transcripts and data charted into categories based on these identified themes. Finally, a process of mapping and interpretation was undertaken.

\section{Results}

Data presented in Table 2 indicates participants' sociodemographic characteristics.

The findings resulted in six main categories. First, contact with the CLP program, access to early diagnosis and timely treatment, perceptions of parents about health personnel on breastfeeding of CLP patients, perceptions of mothers toward breastfeeding, perception of advantages and disadvantages of the NAM technique regarding breastfeeding and assessment of the CLP program.

\section{First contact with the CLP program}

The specialist who detected the anomaly during the second trimester ultrasound referred prenatally diagnosed patients and their parents to the program. The patients who received the diagnosis after birth were referred by friends, family 
members or the medical staff that worked in the hospital were the patient was born.

The interviewed mothers, both prenatally and postnatally, stated the advantages of initiating the process prenatally: tranquility from the counseling of the interdisciplinary team, psychological support, information about the procedures that the child would endure and better acceptance of the infant's condition by the parents:

"I think it was very important because I now assimilate things better, especially the risks and benefits of the whole treatment." [E16]

"We prepared ourselves psychologically so the impact would not be too high, right? That helped us understand the feeding procedure and the process with the obturator." [E27]

\section{Access to early diagnosis and timely treatment}

There are still difficulties for reaching a timely diagnosis, especially for those people who live in rural areas or for pregnant women who access the hospital only at the time of delivery. These factors make early diagnosis difficult.

"I was referred but I had already had the baby." [E14]

"I was referred here but the baby had already been born, he was around 3 months old." [E20] 
Several mothers stated that health professionals and assistants determined the hospitalization, installation of a nasogastric tube or feeding through a baby bottle or syringe, which prevented the first contact between mother and child.

"The problem with the baby was that he was in the hospital and the process stopped, it was suspended and the baby was fed through a tube." [E2]

"To be honest, I did not breastfeed her because the cleft was wide open when she was born. She was taken to the $I C U$, received the tube and was left in the hospital for 10 days. I had missed the opportunity to breastfeed her, I had no milk left." [E17]

The interviewed mothers stated that it seemed as if health professionals considered breastfeeding impossible for these patients, which made the promotion of breastfeeding difficult, despite the recommendations of the World Health Organization (WHO) to breastfeed exclusively up to the six months of age(19).

"Well, a nurse told me that the baby had to be fed with a syringe and a baby bottle so I told her that I wanted to feed him myself and she told me that I was incapable of doing so." [E11]

\section{Perceptions of mothers toward breastfeeding}

Mothers deal with difficulties when they initiate the breastfeeding process since children cannot perform adequate suction. Bottle feeding from an early age, using breast milk from the mother can be used(10). Mothers revealed the efforts to 
perform this process, their frustrations, sadness and despair that caused them the inability to breastfeed their children.

"Hard, it was very, very hard." [E16], [E18]

“Well, sometimes you feel frustrated because you really want to breastfeed her exclusively, both for her sake and for economic reasons." [E27]

Mothers who could start breastfeeding, performed it only for a short period of time. Complications arose quickly for different reasons, which led them to make the decision to abandon breastfeeding altogether.

"I did not have enough breast milk to feed him, although a little came out." [E11]

"There was a time when he was malnourished or so they told me." [E11]

"I feel like nothing comes out. I take a look at his mouth and it is dry, like he does not have enough strength to suction milk." [E1]

Mothers stated other problems, such as inability to suction, how babies hold the nipple, pressure by family members, fear of breastfeeding and even comparisons with previous healthy children who were able to be breastfed for periods of up to 6 months.

"My baby boy could not hold my breast and I did not produce enough breast milk to feed him." [E13]

"I was able to breastfeed my two other children, one up to two years of life and the other up to four." [E16] 
"He loved breast milk, but I had to extract it because he was in the hospital for 8 days and they always fed him through a baby bottle, so I extracted it and gave it to him using the bottle." [E23]

Hospitalization of mothers is also difficult for the breastfeeding practice as the mother-baby bond is broken. In addition, ignorance of this process, especially in new mothers, led to the suspension of breastfeeding.

From the economic standpoint, the access to supplementary milk is an additional cost to mothers of low income and consumption increases as the child grows, which raises such expenses:

"We always prepared the baby bottle with the milk they recommended, but then we could not afford it anymore." [E16]

Despite such difficulties, mothers expressed and recalled the breastfeeding process as a special connection with their children and communicated their sadness because they wanted the process to last longer and be less difficult.

Even though the breastfeeding process is difficult for these mothers, they acknowledged its immense advantages:

"Babies develop better with breast milk, their mental development, their hearing and vision, everything." [E25]

"Everything, I do not know...their growth, the defense system, they are healthier."

"Everything, every vitamin, everything." [E16], [E26] 
Perception of advantages and disadvantages of the nasoalveolar molding

\section{(NAM) technique regarding breastfeeding}

Interviewed mothers considered the use of the NAM advantageous as the obturator allowed a better bottle-feeding process; the palatal cleft was narrower, a nasal molding occurred and weight was gained.

"Now, my baby uses the baby bottle more. It is less difficult and he does not congest as much." [E8]

"My boy has the wing of the nose uplifted, the palatal cleft is almost nonexistent, which helps him a lot." [E5]

"From the moment he received the obturator, he has gained weight and is chubbier." [E11]

The use of the obturator for 24 hours showed no complications for any of the mothers. They did not perceive mood changes or sleep disorders. The cleaning process and its use, in general, were not difficult.

A few mothers, who continued with the breastfeeding process while using the obturator, manifested discomfort and lacerations as the main disadvantage of the obturator. Dermatitis in the child was another disadvantage, but adhesives are necessary to keep the tissues in place and improve the position of the columella.

"When I tried to feed him using the obturator, the little wire poked me, so I decided to remove the device." [E11]

"I was breastfeeding him before using the obturator; once he started using it, I could not feed him anymore. I had to just use the baby bottle." [E12] 
"He developed an allergy and it was horrible for him." [E21]

The correct use of the NAM obturator at home was always concerning as it was a new procedure for the mothers and they wanted to perform it correctly for the well-being of their children. One of the interviewed mothers stated:

"As a suggestion, when they give you the obturator, they should include not only general information, but also recommendations on the product for us to be able to handle the obturator correctly at home." [E15]

\section{Assessment of the CLP program}

The program generates satisfaction, motivation, expectations and happiness to the mothers who initiated this therapy with their children. All of them reported that their children made great progress.

"Wonderful! It has been a beautiful experience because when I realized that my baby was coming with this condition, I never thought that there could be a solution." [E10]

"I am super happy. It is a great happiness because my baby has improved a lot with the obturator." [E28]

Breastfeeding counseling provided by the program was valued as effective but difficult to apply on a daily basis.

"It was effective but it was really a fallacy because there is nothing you can do when the baby is still in the womb. You have to wait until you have the baby, and what you expect is quite different from the real situation." [E15] 
Positive comments were also generated from close family members as they witnessed the progress and acceptance of the child's condition:

"Well, they say everything is ok for the baby." [E6]

"Everybody encourages me a lot. [E20]

\section{Discussion}

A few qualitative studies permitted establishing similarities and differences with the results of the present investigation. The Cartesian approach is still predominant, even though available qualitative data allows further inquiry into the experiences of individuals in specific situations, such as the condition in the current study.

This study revealed difficulties regarding maternal breastfeeding in a sample of UCLP Colombian children who treated at Clínica Noel Foundation in Medellín. Mothers positively valued the information provided by the breastfeeding consultant. However, daily application was difficult. These results are in agreement with those of Lindberg and Berglund(20).

Some factors that discouraged maternal breastfeeding in children younger than 6 months of age included inadequate breastfeeding techniques, frequent use of the baby bottle and early introduction of complementary foods. These factors showed an incidence in the production of breast milk(4) .

The mothers showed great effort in practicing what they learned in the breastfeeding counseling. However, the results of this investigation showed that mothers favored the use of the baby bottle and other techniques over maternal 
breastfeeding. This was due to suction problems, sensation of low levels of milk in their breasts, milk coming out of the baby's nose, social and family pressure, fear that the baby would lose weight and early hospitalization, which do not ease the mother to child bonding. Several of the mentioned reasons were also found in a quantitative study carried out in Porto Alegre (Brazil)(21) and the qualitative study by Lindberg and Berglund(20).

Garcez and Giugliani found that, in spite of the diverse difficulties reported and the lack of professional support after discharge from the maternity wards, the initiation rate and the duration of breastfeeding of children with cleft lip and palate is compatible with successful breastfeeding(21).

Lindberg and Berglund(20) reported that, despite the difficulties, mothers were aware of the importance of breast milk, which is in agreement with the results of the current investigation, such as Colombian mothers. Owens described the feeling of failure manifested by mothers when trying to breastfeed their babies. Mothers found breastfeeding challenging so they needed support, especially when babies showed additional feeding deficiencies(22). A similar finding was reported in our study, where mothers were deal with difficulties during the breastfeeding process.

Amstalden Mendes et al. analyzed counseling to parents during the postnatal period and identified resources used to feed their babies and concluded a lack of attention to UCLP patients by health professionals(23). This study showed that health system factors and maternal-baby factors were the main precipitating reasons why mothers failed to breastfeed. 
Regarding the NAM, Goyal reported a breastfeeding frequency between $44 \%$ and $100 \%$. Mothers who received counseling were more willing to breastfeed compared to mothers who did not receive it ( $72 \%$ vs $44 \%)$. The results of this study showed that treatment with the NAM reduced the breastfeeding practice. In addition, some complications were evident when using the obturator, such as the difficulty of approaching the baby to the breast (25).

Difficult situations with the health personnel due to a negative attitude toward breastfeeding of UCLP children at birth, were reported by Lindberg and Berglund. The Colombian mothers felt low medical support and lack of breastfeeding information.

The breastfeeding of siblings without UCLP was easier in the Scandinavian study (23). In this study, the mothers valued the breastfeeding counseling but they thought that their siblings were easier to feed than the child with CLP.

\section{Conclusions}

In this study, breastfeeding children with CLP was a difficult process, though it was vital and necessary. Thus, efforts should be directed toward a breastfeeding program implementation with pregnancy CLP mothers, so they will have tools that allow them to deal with the expected difficulties during early breastfeeding.

This study revealed that health professionals must not become an obstacle in the mother-child bonding. They should act based on attention protocols formulated according to context and culture. They must provide knowledge and support for 
mothers to make optimal feeding choices, increase mothers' self-efficacy and facilitate breastfeeding success.

An interdisciplinary approach is mandatory, especially during pregnancy, since mothers can feel better prepared to receive their children.

\section{Limitations}

Results of qualitative research cannot be inferred from the general population of mothers with CLP children. Nevertheless, they provide useful information to generate hypotheses of future investigations.

\section{Funding}

Funding for this research project was provided by CES University. CES University did not have a role in the design, interpretations and/or views expressed in this publication.

\section{Conflicts of interest}

The authors report no conflicts of interest.

\section{Acknowledgements}

The authors would like to thank the students who participated in the research; Dr. Juliana Gutierrez and Dr. Lina Rueda. Also, the authors thank the mothers who participated in this program and Fundación Clínica Noel, Medellín, Colombia.

\section{Availability of data and materials}


The dataset or transcripts are available from the corresponding author on reasonable request.

\section{Authors' contributions}

AMCZ and CMMD conceptualized the study and designed data collection methods. GECH did breastfeeding support and consultancy. AMCZ supervised collected data and CMMD performed qualitative analysis of the study and performed statistical analysis of the data. AMCZ and CMMD contributed to writing the manuscript. All authors critically reviewed and approved of the final manuscript.

\section{Ethics approval and consent to participate}

Ethics approval for this study was obtained from the Biomedical Research Ethics Committee at CES University minutes 74,2014 . All participants signed a consent form before the study began and voluntarily participating in the study. For participants who were younger than 18 years, written consent was obtained from a parent or legal guardian and assent from the participant. To preserve anonymity, codes were assigned to each participant based on the area, type of participant and number of the visit. Audio recordings and transcripts were stored at CES University in a password protected file.

\section{Consent for publication}

Not applicable 


\section{REFERENCES}

1. Mossey PA, Little J, Munger RG, Dixon MJ, Shaw WC. Cleft lip and palate. Lancet. 2009;374:13.

2. Kadir A, Mossey PA, Orth M, Blencowe H, Sowmiya M, Lawn JE, et al. Systematic review and meta-analysis of the birth prevalence of orofacial clefts in low- and middle-income countries. Cleft Palate Craniofac J. 2017;54(5):571-81.

3. Kaye A, Lybrand S, Chew WL. Assessment and management of Psychosocial Needs: Social work utilization in comprehensive cleft team care. Cleft Palate Craniofac J.2018;55(8):1081-91.

4. Duarte GA, Ramos RB, Cardoso MC de AF. Feeding methods for children with cleft lip and/or palate: a systematic review. Braz J Otorhinolaryngol. 2016;82(5):602-9.

5. Ha S, Jung S, Koh KS. Effect of vowel context on test-retest nasalance score variability in children with and without cleft palate. Int J Pediatr Otorhinolaryngol. 2018;109:72-7.

6. Vig KWL, Mercado AM. Overview of orthodontic care for children with cleft lip and palate, 1915-2015. Am J Orthod Dentofacial Orthop. 2015;148(4):543-56.

7. Klassen AF, Tsangaris E, Forrest CR, Wong KWY, Pusic AL, Cano SJ, et al. Quality of life of children treated for cleft lip and/or palate: A systematic review. J Plast Reconstr Aesthet Surg. 2012;65(5):547-57.

8. American Academy of Pediatrics. Breastfeeding and the use of human milk. Pediatrics. 2012;129(3):e827-41.

9. Luby JL, Belden AC, Whalen D, Harms MP, Barch DM. Breastfeeding and childhood IQ: The mediating role of gray matter volume. J Am Acad Child Adolesc Psychiatry. 2016;55(5):367-75.

10. Reilly S, Reid J, Skeat J, Cahir P, Mei C, Bunik. Guidelines for Breastfeeding Infants with cleft lip, cleft palate, or cleft lip and palate. Breastfeed Med. 2013;8(4):349-53.

11. Smedegaard LHV, Marxen DRN, Moes JHV, Glassou EN, Scientsan C. Hospitalization, breast-milk feeding, and growth in infants with cleft palate and cleft lip and palate born in Denmark. Cleft Palate Craniofac J. 2008;45(6):628-32.

12. López-Palacio A, Cerón-Zapata A, Gómez D, Dávila-Calle A, Ojalvo-Arias M. Nasal Changes With Nasoalveolar Molding in Colombian Patients With Unilateral Cleft Lip and Palate. 2012; 34(3):239-44.

13. Cerón-Zapata AM, López-Palacio AM, Rodriguez-Ardila MJ, Berrio- 
Gutiérrez LM, De Menezes M, Sforza C. 3D evaluation of maxillary arches in unilateral cleft lip and palate patients treated with Nasoalveolar Moulding vs. Hotz's plate. J Oral Rehabil. 2016; 43(2):111-8.

14. Mancini L, Gibson TL, Grayson BH, Flores RL, Staffenberg D, Shetye PR. Three-dimensional soft tissue nasal changes after Nasoalveolar Molding and primary cheilorhinoplasty in infants with unilateral cleft lip and palate. Cleft Palate Craniofac J. 2019;56(1):31-8.

15. Nelson PA, Kirk SA, Caress A-L, Glenny A-M. Parents' emotional and social experiences of caring for a child through cleft treatment. Qual Health Res. 2012;22(3):346-59.

16. Nelson p, Glenny A, Kirk S, Caress A. Parents' experiences of caring for a child with a cleft lip and/or palate: a review of the literature. Child Care Health Dev. 2012;38(1):6-20.

17. Olson K, Young RA, Schultz IZ. Handbook of Qualitative Health Research for Evidence-Based Practice. New York: Springer; 2016.

18. Bennett $D$, Barret $A$, Helmich $E$. How to analyse qualitative data in different ways. Clin Teach. 2019; 16(1):7-12

19. WHO. Maternal, infant and young child nutrition. Comprehensive implementation plan on maternal, infant and young child nutrition: biennial report. 2018.

20. Lindberg N, Berglund A-L. Mothers' experiences of feeding babies born with cleft lip and palate. Scand J Caring Sci. 2014;28(1):66-73.

21. Garcez LW, Giugliani ERJ. Population-based study on the practice of breastfeeding in children born with cleft lip and palate. Cleft Palate Craniofac J. 2005;42(6):687-93.

22. Owens J. Parents' experiences of feeding a baby with cleft lip and palate. $\mathrm{Br}$ J Midwifery. 2008;16(12):778-84.

23. Amstalden-Mendes LG, Magna LA, Gil-da-Silva-Lopes VL. Neonatal care of infants with cleft lip and/or palate: Feeding orientation and evolution of weight gain in a nonspecialized Brazilian Hospital. Cleft Palate Craniofac J. 2007;44(3):329-34. 
Table 2. Sociodemographic Characteristics of Children With unilateral Cleft Lip Lip and Palate who participated in the study $(n=28)$

\begin{tabular}{|c|c|c|}
\hline Variable & $n(\%)$ & Me (lqR) \\
\hline $\begin{array}{l}\text { Sex of the child } \\
\text { Male } \\
\text { Female }\end{array}$ & $\begin{array}{l}20(71,4 \%) \\
8(28,6 \%)\end{array}$ & \\
\hline $\begin{array}{l}\text { Age of the child (months) } \\
\text { Newborn } \\
\text { One month } \\
\text { Two months } \\
\text { Three months }\end{array}$ & $\begin{array}{l}10(35,7 \%) \\
6(21,4 \%) \\
8(28,6 \%) \\
4(14,3 \%)\end{array}$ & \\
\hline $\begin{array}{l}\text { Place of residence } \\
\text { Urban } \\
\text { Rural } \\
\text { Omitted }\end{array}$ & $\begin{array}{l}18(64,3 \%) \\
4(14,3 \%) \\
6(21,4 \%)\end{array}$ & \\
\hline $\begin{array}{l}\text { Parents' age (years) } \\
\text { Mother } \\
\text { Father }\end{array}$ & & $\begin{array}{l}32(21-44) \\
33(20-51)\end{array}$ \\
\hline $\begin{array}{l}\text { Mother education } \\
\text { None } \\
\text { Completed primary school } \\
\text { Completed secondary school } \\
\text { Technology } \\
\text { Completed university } \\
\text { Omitted }\end{array}$ & $\begin{array}{l}7(25,0 \%) \\
1(3,6 \%) \\
1(3,6 \%) \\
9(32,1 \%) \\
7(25,0 \%) \\
3(10,7 \%)\end{array}$ & \\
\hline $\begin{array}{l}\text { Father education } \\
\text { None } \\
\text { Completed primary school } \\
\text { Completed secondary school } \\
\text { Technology } \\
\text { Completed university } \\
\text { Omitted }\end{array}$ & $\begin{array}{l}7(25,0 \%) \\
3(10,7 \%) \\
10(35,7 \%) \\
3(10,7 \%) \\
1(3,6 \%) \\
4(14,3 \%)\end{array}$ & \\
\hline
\end{tabular}




\begin{tabular}{|c|c|}
\hline $\begin{array}{l}\text { Mother occupation } \\
\text { Housewife } \\
\text { Unemployed } \\
\text { Self employed } \\
\text { Employed } \\
\text { Others } \\
\text { Omitted }\end{array}$ & $\begin{array}{l}10(35,7 \%) \\
9(32,1 \%) \\
1(3,6 \%) \\
7(25,0 \%) \\
1(3,6 \%) \\
0(0 \%)\end{array}$ \\
\hline $\begin{array}{l}\text { Father occupation } \\
\text { Househusband } \\
\text { Unemployed } \\
\text { Self employed } \\
\text { Employed } \\
\text { Others } \\
\text { Omitted }\end{array}$ & $\begin{array}{l}0(0 \%) \\
11(39,3 \%) \\
1(3,6 \%) \\
5(17,9 \%) \\
10(35,7 \%) \\
1(3,6 \%)\end{array}$ \\
\hline $\begin{array}{l}\text { Place occupied by the child in the family (birth } \\
\text { number) } \\
\text { First } \\
\text { Second } \\
\text { Third } \\
\text { Omitted }\end{array}$ & $\begin{array}{l}10(35,7 \%) \\
5(17,9 \%) \\
10(35,7 \%) \\
3(10,7 \%)\end{array}$ \\
\hline $\begin{array}{l}\text { Skin to skin contact the first hour } \\
\text { Yes } \\
\text { No } \\
\text { Omitted }\end{array}$ & $\begin{array}{l}13(46,4 \%) \\
5(17,9 \%) \\
10(35,7 \%)\end{array}$ \\
\hline $\begin{array}{l}\text { With the anterior question, If the answer was } \\
\text { yes, the mother can breastfeeding the baby } \\
\text { during the first hour of life. } \\
\text { Yes } \\
\text { No } \\
\text { Omitted }\end{array}$ & $\begin{array}{l}5(38,5 \%) \\
8(61,5 \%) \\
0(0 \%)\end{array}$ \\
\hline
\end{tabular}




\begin{tabular}{|l|l|l|}
\hline Feeding form the first six months of life & \\
Exclusive breastfeeding & $0(0 \%)$ & \\
Breastfeeding and bottle & $6(21,4 \%)$ \\
Bottle & $6(21,4 \%)$ & \\
Cup & $0(0 \%)$ & \\
Dropper & $1(3,6 \%)$ & \\
Syringe & $1(3,6 \%)$ & \\
Nasogastric tube & $8(14,3 \%)$ & \\
Omitted & $6(21,4 \%)$ & \\
\hline
\end{tabular}

